\title{
ETNOBOTÁNICA AONIK'ENK (TEHUELCHES DE SANTA CRUZ) INÉDITA DE RAÚL MARTÍNEZ CROVETTO (II) Y COMPILACION DE FUENTES SECUNDARIAS: USOS Y PRÁCTICAS ASOCIADAS A LAS PLANTAS
}

\author{
Gustavo F. Scarpa', Cintia N. Rosso ${ }^{1}$ \& Leonardo M. Anconatani ${ }^{2}$
}

\begin{abstract}
${ }^{1}$ Museo Argentino de Ciencias Naturales "Bernardino Rivadavia”, Ángel Gallardo 470, $2^{\circ}$ piso, 1405 Buenos Aires, Argentina; gustavo22et@yahoo.com.ar (autor corresponsal).

2 Cátedra de Farmacobotánica y Museo de Farmacobotánica “Juan A. Domínguez”, Facultad de Farmacia y Bioquímica, Universidad de Buenos Aires, Junín 954, 1113 Buenos Aires, Argentina.
\end{abstract}

\begin{abstract}
Scarpa, G. F.; C. N. Rosso \& L. M. Anconatani. 2020. The unpublished Aonik'enk (tehuelches of Santa Cruz) ethnobotany of Raúl Martínez Crovetto (II) and compilation from secondary sources: Uses and practices associated with plants. Darwiniana, nueva serie 8(1): 5-22.
\end{abstract}

Unpublished data from Raúl Martínez Crovetto on plant practices and meanings among the Aonik'enk people of Santa Cruz documented during 1967, were found at the Institute of Botany of the Northeast (IBONE). Its value is a priori remarkable in view of the limited background on ethnobotany of this human group. The aims of this study were to value, analyze, update and interpret the voluminous set of information documented at fieldwork by Martínez Crovetto, to compile and classify the scattered data found in the literature on the subject, and to compare these data with those referred to for the Selk'nam (onas) of Tierra del Fuego. The methodology corresponds to historical ethnobotany, which considers data from the past as a primary source of information on which the classical ethnobotanical method is applied. A total of 163 data on Aonik'enk ethnobotany from Raúl Martínez Crovetto's field records were valued, as well as 105 from published secondary sources consulted. In total, 244 different ethnobotanical data about this people are referred for 117 botanical taxa. Most ethnobotanic uses were food $(90 ; 36.7 \%)$ and medicinal $(81 ; 33 \%)$. The coincidence between the Aonik'enk and Selk'nam data exceeds $60 \%$, indicating the existence of links between their ethnobotany. This contribution is the greatest input into Aonik'enk ethnobotany both for the amount and diversity of data compiled, and for the volume of new unpublished data informed. Edible uses of Rumex species roots and of Chuquiraga avellanedae aerial part are cited here for the first time for Argentina, as well as Mulguraea tridens roots for making of combs.

Keywords. Aonik'enk; historical ethnobotany; Patagonia; Santa Cruz.

Resumen. Scarpa, G. F.; C. N. Rosso \& L. M. Anconatani. 2020. Etnobotánica Aonik'enk (tehuelches de Santa Cruz) inédita de Raúl Martínez Crovetto (II) y compilación de fuentes secundarias: Usos y prácticas asociadas a las plantas. Darwiniana, nueva serie 8(1): 5-22.

En el Instituto de Botánica del Nordeste (IBONE) se hallaron datos inéditos de Raúl Martínez Crovetto sobre prácticas y significaciones de las plantas entre los Aonik'enk de Santa Cruz documentadas durante 1967. Su valor resulta a priori destacable en vistas a los escasos antecedentes sobre la etnobotánica de este grupo humano. El objetivo es poner en valor, analizar, actualizar e interpretar el voluminoso conjunto de informaciones documentadas a campo por Martínez Crovetto, recopilar y clasificar los datos dispersos hallados en la bibliografía sobre la temática y comparar estos datos con los referidos para los Selk'nam (onas) de Tierra del Fuego. La metodología corresponde a la etnobotánica histórica, la cual considera a los datos del pasado como una fuente de información primaria sobre los cuales se aplica el método etnobotánico clásico. Se ponen en valor un total de 163 datos sobre la etnobotánica Aonik'enk 
procedentes de los registros de campo de Raúl Martínez Crovetto, así como 105 provenientes de fuentes secundarias publicadas consultadas. En total se identifican 244 datos etnobotánicos diferentes sobre este pueblo referidos a 117 taxa botánicos. La mayor parte de los usos son alimenticios $(90 ; 36,7 \%)$ y medicinales $(81 ; 33 \%)$. La coincidencia entre los datos Aonik'enk y Selk'nam asciende a más del $60 \%$, lo cual indica la existencia de vinculaciones entre ambas etnobotánicas. Esta contribución constituye el mayor aporte a la etnobotánica Aonik'enk, tanto por la cantidad y diversidad de datos compilados como por el número de nuevos datos inéditos informados. Se citan por vez primera para la Argentina los usos comestibles de raíces de una especie del género Rumex y de la parte aérea de Chuquiraga avellanedae, así como las raíces de Mulguraea tridens para la confección de peines.

Palabras clave. Aonik'enk; etnobotánica histórica; Patagonia; Santa Cruz.

\section{INTRODUCCIÓN}

Apesar de los importantes avances experimentados por la disciplina etnobotánica durante las últimas décadas, existen todavía numerosas áreas o complejos bioculturales de la Argentina cuyo abordaje bajo esta perspectiva resulta inexistente. Es decir, todavía desconocemos las formas en que determinados grupos humanos que pueblan o poblaron su territorio interactúan con la vegetación nativa, tal como ocurre con los indígenas Aonik'enk o Tehuelches que habitaban la provincia de Santa Cruz. Se han hallado en los archivos de Raúl Martínez Crovetto conservados en la biblioteca del Instituto de Botánica del Nordeste (IBONE-CONICET) numerosos datos inéditos acerca de la etnobotánica de este grupo étnico documentados por dicho autor durante el año 1967 en distintas localidades de la provincia de Santa Cruz. Una parte de ellos, referentes a la fitonimia, fueron analizados e interpretados en un trabajo reciente de los autores (Scarpa et al., 2020), el cual constituye la primera contribución sobre esta temática para los Aonik'enk. Sin embargo, la información inédita hallada incluye además numerosos datos sobre los usos y significaciones de las plantas de variada índole que, junto a una importante cantidad de otros datos compilados de referencias bibliográficas, constituyen el objeto de este artículo.

Los pueblos indígenas que habitaban la provincia de Santa Cruz fueron históricamente considerados bajo el etnónimo genérico de Tehuelches (o Patagones) por la mayoría de los autores y particularizados como "de la tierra firme" (Escalada, 1949) o "meridionales" o "del sur" (Casamiquela, 1965). La parcialidad que habitaba al norte del Estrecho de Magallanes hasta el río Santa Cruz fue particularizada con el etnónimo específico de
Aônükün'k (Vignati, 1936), Aóeni kenk (Harrington, 1946), o Aonik'énk (Escalada, 1949, Casamiquela, 1965). Nacuzzi (2005) informa que este pueblo era nómade cazador-recolector "de raíces, tubérculos y algunos pocos frutos. Su industria estaba limitada al trabajo de la piedra, al curtido de cuero y a la rústica confección de utensilios de madera". Habitaban particularmente la estepa patagónica, aunque su territorio de nomadismo incluía también la costa marítima y el bosque subantártico. Tenían una organización socio-política de bandas patrilineales lideradas por caciques locales. Los cambios producidos a partir de la adopción del caballo modificaron aspectos de las técnicas de caza, las armas y la alimentación (Siffredi \& Matarrese, 2004). En el transcurso del siglo XIX se incorporaron a los mercados regionales como proveedores de plumas y cueros y consumidores de bebidas alcohólicas y de otros productos manufacturados (Palermo, 1986). A finales de ese siglo, las campañas militares junto a la acción evangelizadora llevaron a la desarticulación socio-económica y política de los Aonik'enk, así como a la reducción de sus territorios, la creación de reservas, educación en colegios salesianos e inserción en el mercado laboral como asalariados (Rodríguez \& Del Río, 2000; Siffredi $\&$ Matarrese, 2004). En la actualidad, algunos de sus representantes viven en el paraje Camusu Aike desempeñándose como jornaleros temporales en las estancias o en puestos fijos mensuales, mientras que otros trabajan como empleados del sector público o privado en las ciudades (Rodríguez et al., 2016). De su lengua, el Aaonek'o 'ayen o Tehuelche (familia lingüística Chon), quedaban alrededor de 1980 unos pocos hablantes, quienes entonces no la empleaban de manera habitual, sino que simplemente la recordaban (Fernández Garay, 1998). 
Según Censabella (1999) a finales del siglo XX se desconocía el número de personas pertenecientes a este grupo étnico, variando su estimación de acuerdo con los investigadores. Según el Registro Nacional de Comunidades Indígenas dependiente de la Secretaría de Cultura de la Nación (2018), en la actualidad existiría un solo núcleo de Tehuelches propiamente dichos en el centro del Departamento Güer Aike $\left(50^{\circ} 65^{\prime}\right.$ lat. S, $70^{\circ} 75^{\prime}$ long. W) y otros tres categorizados como Mapuche-Tehuelches en las inmediaciones de los municipios de Río Gallegos, Puerto Santa Cruz y 28 de Noviembre de la misma jurisdicción departamental en la provincia de Santa Cruz. En síntesis, los Aonik'enk pertenecerían al conjunto de pueblos originarios de la Argentina (como los Tonocotés, Gününa küna, Vilelas y otros) cuyas lenguas se hallan seriamente amenazadas (Viegas Barros, 2011) y que se encuentran en un proceso de re-etnización.

Si bien contamos con abundantes referencias históricas sobre este grupo étnico provenientes tanto de exploradores (compiladas por Martinič, 1995), como de naturalistas (Onelli, 1904; Lista, 1975; 2006), etnógrafos (Lehmann-Nitsche, 1908; Escalada, 1949; Casamiquela, 1965; Siffredi \& Matarrese, 2004), ethnohistoriadores (Rodríguez \& Del Río, 2000; Saletta, 2015; Lazzari \& Quarleri, 2015), arqueobotánicos (Ciampagna, 2014; Belardi et al., 2013) y lingüistas (Censabella, 1999; Fernández Garay, 2004), los antecedentes sobre su etnobotánica son realmente escasos a excepción del trabajo pionero antes mencionado (Scarpa et al., 2020). En efecto, solo hallamos para los Aonik'enk menciones episódicas y fragmentarias sobre algunos pocos usos de plantas científicamente identificadas en los trabajos de exploradores, misioneros religiosos, naturalistas e historiadores como Fitz Roy (1839), Spegazzini (1884), Hesketh-Prichard (1902), Onelli, (1904), Outes (1905), LehmannNitsche (1908), Escalada (1949), Musters (1964), Schmid (1964) [1858/65], Lista (1975; 2006), Martinič (1995) y Childs (1997) [1936].

Spegazzini (1884) ha considerado la existencia de profundas relaciones interétnicas entre los Aonik'enk y los Selk'nam u Onas de Tierra del Fuego quienes fueron vecinos (separados solamente por el Estrecho de Magallanes), ya que los asentamientos de los primeros llegaban hasta la península de Brunswick en la XII ${ }^{\mathrm{a}}$ Región chilena de Magallanes (según
Martinič, 1995). En efecto, Spegazzini (1884: 226) sostiene que "Los Aóna [Ona] y los Aónik(e)n son hermanos, sin duda, y lo hace suponer el nombre, la lengua, las formas del cuerpo, y los rastros de tradición que aún existen entre ellos". Por esto último, y porque contamos con un estudio etnobotánico sobre los Selk'nam (Onas) -documentado a campo durante enero de 1965- publicado también por Raúl Martínez Crovetto (1968), decidimos efectuar una comparación exhaustiva entre los usos de las plantas de ambos grupos étnicos.

Esta contribución tiene por objetivos poner en valor, analizar, actualizar e interpretar el voluminoso conjunto de informaciones de Martínez Crovetto acerca de los usos, significaciones y prácticas asociadas a las plantas de los indígenas Aonik'enk que hasta hoy permanecen inéditas, recopilar, ordenar y clasificar los datos dispersos hallados en la bibliografía mencionada y comparar estos datos con los referidos para los Selk'nam de Tierra del Fuego. La cumplimentación de estos objetivos significaría un gran aporte para la revalorización del patrimonio cultural de este pueblo, así como para mejorar sustancialmente la comprensión de la etnobotánica de este grupo humano.

\section{MATERIALES Y MÉTODOS}

Las fuentes primarias empleadas en este trabajo corresponden a datos etnobotánicos hallados como resultado de un análisis minucioso del voluminoso corpus de documentos y materiales que conforman los archivos de MC. Dichos datos se hallaron consignados en fichas y libretas de campo manuscritas de MC conservadas dentro de cajas de archivo en la Biblioteca del Instituto de Botánica del Nordeste (IBONE; Universidad Nacional del Nordeste CONICET) de la ciudad de Corrientes. El acceso a dicho archivo fue facilitado a uno de nosotros (G. F. Scarpa) en abril de 2010 por el director de dicha institución, en ese entonces, el Ing. Agr. Antonio Krapovickas. La descripción y análisis de los datos etnobotánicos inéditos hallados en estos documentos se consideran resultados de este trabajo, por lo cual son referidos en el acápite correspondiente. Todos los datos obrantes en las fichas y libretas fueron ordenados y clasificados en una base de datos que responde al programa MS-Access. 
Por otra parte, se efectuó una búsqueda pormenorizada de los ejemplares vegetales coleccionados en compañía de los entrevistados Aonik'enk citados por MC en el Herbario de Plantas Vasculares del IBONE (CTES) de la provincia de Corrientes (donde era habitual que MC depositara los mismos) y a través de la consulta al listado de las colecciones de herbario del sitio web del Instituto de Botánica Darwinion de San Isidro, provincia de Buenos Aires (IBODA-CONICET; http://conosur. floraargentina.edu.ar/collections). Esto último fue efectuado tanto con el fin de poder citar el material vegetal que documenta las informaciones etnobotánicas que aquí se reproducen, como a los fines de obtener identificaciones botánicas más actualizadas a las citadas por MC, teniendo en cuenta que los materiales habían sido depositados hace ya más de 50 años.

Respecto a las identificaciones botánicas referidas por $\mathrm{MC}$ se procedió en primera instancia a verificar la validez del binomio, su inclusión como "aceptado" para el Catálogo de las Plantas Vasculares del Cono Sur (Zuloaga et al., 2019; actualizado permanentemente en http://conosur.floraargentina. edu.ar), su distribución en la provincia de Santa Cruz y su actualización en caso de su condición de sinónimo. Se emplearon además para ello las bases de datos Tropicos del Missouri Botanical Garden (2019) y The Plant List (2013) para plantas vasculares y las bases de datos GBIF (2019), MycoBank Database (2019) y Species Fungorum (2019) para hongos y líquenes. En casos de identificación botánica hasta nivel de género que fueran acompañados de un nombre vulgar, consideramos como válidas las identificaciones a nivel específico que se citan en la bibliografía, solamente en los casos en que coincidieran las correspondencias entre ambos tipos de nombres y sus aplicaciones específicas, p.e. Azorella trifurcata citado por Fitz Roy en la obra de Martinič (1995: 236). Sin embargo, se comprobó que en ciertos casos, binomios citados en la bibliografía ya no resultan aceptados o son desconocidos por la botánica contemporánea, p.e. Chenopodium ameghinoi citado por Outes (1905), razón por la cual, los datos etnobotánicos referidos a dicho taxón fueron descartados.

En cuanto a la compilación de datos Aonik'enk dispersos en la bibliografía publicada, empleamos como criterios para su inclusión considerar: a) solo a aquellos autores que hayan referido datos etnobotánicos que se puedan adscribir con seguridad a los Aonik'enk y no aquellos que refieren a Tehuelches o Patagones sensu lato. Esto es debido a lo inespecífico de estos etnónimos genéricos los cuales podrían llegar a incluir a otros grupos indígenas propios de la provincia de Buenos Aires, Río Negro, Neuquén y de Chubut que claramente no pertenecen a los Aonik'enk; b) datos que refieran a taxa botánicos cuya identificación científica resulte precisa, al menos a nivel de género. Las fuentes bibliográficas utilizadas en este trabajo corresponden al período que va desde fines del siglo XIX a la primera mitad del siglo XX, tiempo en que las misiones religiosas, las exploraciones de viajeros, científicos y derivadas de campañas militares fueron muy comunes en la región patagónica. Estas actividades estuvieron motivadas no solo por el interés que despertaba en naturalistas $\mathrm{y}$ etnógrafos su exotismo -quienes buscaban delimitar grupos y describir sus características culturales-, sino además por considerarse un área ambicionada por el Estado nacional para ser colonizada (Rodríguez \& Del Río, 2000; Nacuzzi, 2005). Estas motivaciones dieron lugar a trabajos que representan tanto los postulados de la época (nociones de orden, progreso y evolución, construcción del Estado-Nación) como los intereses de quienes los realizaron, ya sean misioneros (Schmid, 1964 [1858/65]), naturalistas o etnógrafos (Spegazzini, 1884; Onelli, 1904; Outes, 1905; Lehman-Nistche, 1908; Escalada, 1949; Embon, 1950; Lista, 1975; 2006) o exploradores y viajeros (Fitz Roy, 1839; Roncaglia, 1884, Hesketh-Prichard, 1902; Childs, 1997 [1936]) o historiadores (Martinič, 1995).

En el análisis de los datos se empleó el método propio de la etnobotánica histórica, el cual considera a los datos del pasado como una fuente de información primaria sobre los cuales se aplica el método clásico etnobotánico (ver Rosso, 2012 y Rosso \& Scarpa, 2012). Mediante este método se procura trascender la simple editorialización $\mathrm{y}$ ordenamiento de la información histórica, al contextualizar los datos presentados y analizados desde las perspectivas espacio-temporal y sociocultural, al actualizar y mejorar las identificaciones botánicas de los taxa referidos. 
La comparación entre los datos etnobotánicos Aonik'enk aquí descritos con aquellos correspondientes a los Selk'nam (Onas) de Tierra del Fuego se efectúa a nivel cuantitativo entre las categorías de uso referidas, especies compartidas, usos idénticos y en función del cociente entre estos últimos y la cantidad de especies compartidas. Al limitarse a estas últimas, el cálculo de las semejanzas entre ambos grupos étnicos procura independizarse de la variabilidad de especies vegetales sobre las que se inquirió en uno y otro caso, resaltando el aspecto cultural que adquieren las significaciones referidas para cada una de ellas.

\section{Material examinado}

Adesmia boronioides Hook. f.

ARGENTINA. Santa Cruz. Depto. Güer Aike. I-1967, Martínez Crovetto P-15 (SI).

Arjona patagonica Hombr. \& Jacq. ex Decne.

ARGENTINA. Santa Cruz. Depto. Río Chico, Gob. Gregores, I-1967, Martínez Crovetto P-132 (CTES 152042).

Arjona tuberosa Cav.

ARGENTINA. Santa Cruz. Depto. Río Chico, Gob. Gregores, I-1967, Martínez Crovetto P-145 (CTES 152026).

Elymus magellanicus (E. Desv.) A. Löve

ARGENTINA. Santa Cruz. Depto. Güer Aike, Río Gallegos, I-1967, Martínez Crovetto P-36 (CTES). Ephedra sp.

ARGENTINA. Santa Cruz. Depto. Güer Aike, Río Gallegos, I-1967, Martínez Crovetto P-22 (CTES 268392).

Gamocarpha australis (Decne.) S.S. Denham \& Pozner

ARGENTINA. Santa Cruz. Depto. Güer Aike. Pje. Camusú Aike, I-1967, Martínez Crovetto P-62 (CTES 03361); Pje. Camusú Aike, I-1967, Martínez Crovetto P-85 (CTES 97587).

Hypochaeris incana (Hook. \& Arn.) Macloskie ARGENTINA. Santa Cruz. Depto. Güer Aike, Río Gallegos, I-1967, Martínez Crovetto P-12 (CTES). Juncus aff. balticus Willd.

ARGENTINA. Santa Cruz. Depto. Lago Argentino, Calafate, I-1967, Martínez Crovetto P-106 (CTES 304091).

Limonium brasiliense (Boiss.) Kuntze

ARGENTINA. Santa Cruz. Depto. Güer Aike,
Río Gallegos, I-1967, Martínez Crovetto P-32 (CTES 217031).

Lycium ameghinoi Speg.

ARGENTINA. Santa Cruz. Depto. Güer Aike, Río Gallegos, I-1967, Martínez Crovetto P-141 (CTES 144469).

Mentha spicata $\mathrm{L}$. var. rotundifolia $\mathrm{L}$.

ARGENTINA. Santa Cruz. Depto. Lago Argentino, Calafate, I-1967, Martínez CrovettoP-110 (CTES 211434).

Pappostipa ibarii (Phil.) Romasch.

ARGENTINA. Santa Cruz. Depto. Güer Aike, Río Gallegos, I-1967, Martínez Crovetto P-17 (CTES 204968).

Rumex sp.

ARGENTINA. Santa Cruz. Depto. Güer Aike. Pje. Camusú Aike, I-1967, Martínez Crovetto P-97 (CTES 142299).

Rumex acetosella $\mathrm{L}$.

ARGENTINA. Santa Cruz. Depto. Güer Aike, Río Gallegos, I-1967, Martínez Crovetto P-29 (CTES 142316).

Senecio patagonicus Hook. \& Arn.

ARGENTINA. Santa Cruz. Depto. Güer Aike, Río Gallegos, I-1967, Martínez Crovetto P-14 (CTES 00956); Depto. Lago Argentino, Pje. Vega Piayet, I-1967, Martínez Crovetto P-114 (CTES 00957).

Senecio neaei DC.

ARGENTINA. Santa Cruz. Depto. Güer Aike, Río Gallegos, I-1967, Martínez Crovetto P-150 (CTES); Pje. Camusú Aike, I-1967, Martínez Crovetto P-79 (CTES).

Senecio trifurcatus (G. Forst.) Less.

ARGENTINA. Santa Cruz. Depto. Güer Aike, Río Gallegos, I-1967, Martínez Crovetto P-4 (CTES 00872).

Stipa sp.

ARGENTINA. Santa Cruz. Depto. Güer Aike, Pje. Camusú Aike, I-1967; Martínez Crovetto P-60 (CTES 341139); Pje. Camusú Aike, I-1967; Martínez Crovetto P-70 (CTES 341138).

Taraxacum officinale F.H. Wigg.

ARGENTINA. Santa Cruz. Depto. Güer Aike. Pje. Camusú Aike, I-1967, Martínez Crovetto P-82 (CTES 00373)

Verbena sp.

ARGENTINA. Santa Cruz. Depto. Río Chico, Gob. Gregores, I-1967, Martinez Crovetto P-131 (CTES). 


\section{RESULTADOS}

Análisis de los datos inéditos y de las identificaciones botánicas

El análisis de los materiales hallados evidenció la existencia de dos grupos de fichas: unas encabezadas con el rótulo: Fichas nombre tehuelches - latinos, inicializadas en su borde superior izquierdo por un fitónimo Aonik'enk, donde se indican las correspondencias botánicas respectivas de cada uno de los fitónimos indígenas. En varios casos, algunas de ellas incluyen un número precedido de la letra $\mathrm{P}$ - (que refiere a un ejemplar de herbario) $\mathrm{y}$, en ocasiones, el significado en castellano del nombre Aonik'enk de cada planta. Se pudo distinguir, además, otro conjunto de fichas encabezadas por el rótulo: Nombres latino-tehuelches - Total 191, las cuales se encuentran inicializadas, en su borde superior izquierdo, por un nombre científico incluido el nombre indígena al que hacía referencia, seguido de una descripción de una o más aplicaciones (a veces formas de preparación, partes utilizadas y formas de consumo), un número de herbario precedido por la letra $\mathrm{P}-\mathrm{y}$ un número de entrevista. Por otro lado, entre las libretas de campo originales de MC se halló una rotulada como "Cuaderno de los Tehuelches del sur (Santa Cruz) o Aonikengs". En este figuran transcriptos los datos recabados a campo en las entrevistas realizadas, ordenados por el nombre indígena de la planta, liquen u hongo. Cada entrevista se halla numerada e incluye el nombre completo de la persona entrevistada, la localidad y fecha de obtención de las informaciones y una cantidad antecedida del signo $\$$, que correspondería al pago que MC le habría propinado al colaborador. A partir de la comparación de los datos ordenados en base de datos provenientes de las fichas y de las libretas pudimos comprobar que gran parte de los mismos resultaban similares, a excepción de algunos pocos datos suplementarios. En total figuran 18 entrevistas efectuadas a 18 colaboradores consultados durante el mes de enero del año 1967 en las localidades de Río Gallegos y Paraje Camusú Aike del Departamento Güer Aike, en Tres Lagos y Paraje Vega Piayet (ex reserva Lago Viedma o Lote 119) del Departamento Lago Argentino y en Gobernador Gregores y Paraje Lote 6 (ex reserva Lago Cardiel o Lote 6) del Departamento Río Chico, todas ellas en la provincia de Santa Cruz (Fig. 1).

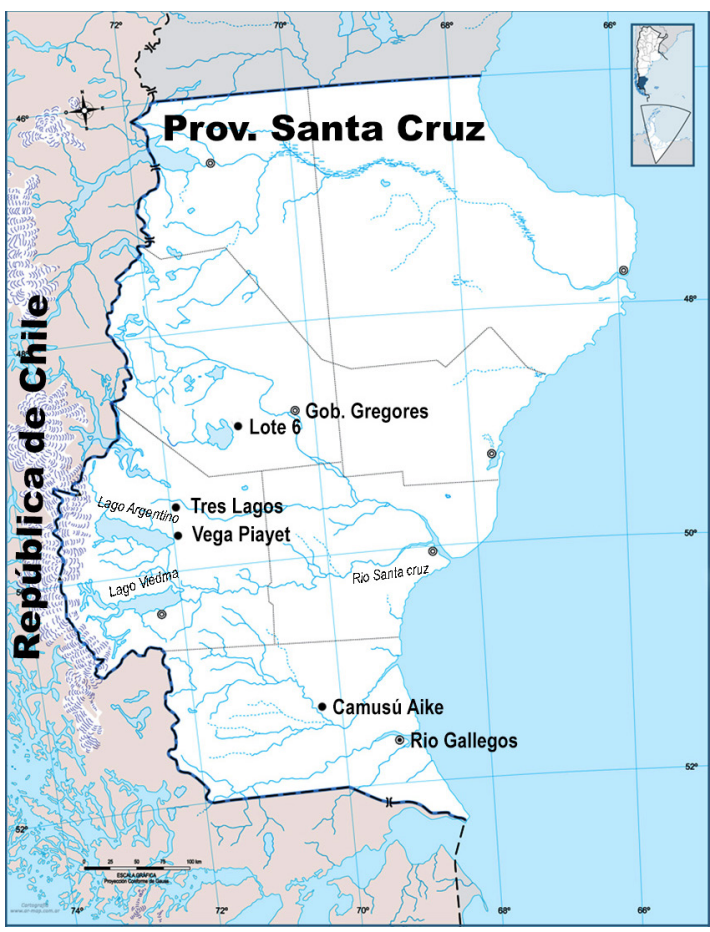

Fig. 1. Localidades y parajes donde R. Martínez Crovetto realizó sus entrevistas. Figura en color en la versión en línea http://www.ojs.darwin.edu.ar/index.php/darwiniana/ article/view/867/1183

Se pudo localizar una parte importante de los ejemplares de herbario coleccionados por $\mathrm{MC}$ en la provincia de Santa Cruz, tanto en el Herbario del IBONE (bajo la sigla CTES) como en la base de datos del Instituto de Botánica Darwinion (IBODA) (bajo la sigla SI). En las etiquetas de los ejemplares consultados coinciden, además de los datos del colector y la provincia, los de las localidades señaladas en los cuadernos, las fechas (enero de 1967) y el código particular de colecta antes mencionado $\left(\mathrm{P}-\mathrm{n}^{\mathrm{o}}\right)$. De esto último se desprende, de manera inequívoca, que estos ejemplares constituyen la documentación del material botánico de los datos de las entrevistas antes mencionadas. Se pudieron ampliar identificaciones botánicas de $\mathrm{MC}$ efectuadas hasta el nivel de género, sobre la base de la consulta a la Flora Patagónica (Correa, 1984). Tal es el caso del taxón referido 
por MC como Lepidophyllum sp., la cual se trataría indudablemente de Lepidophyllum cupressiforme (Lam.) Cass, nombre actual de la única especie de dicho género que se encuentra en la Patagonia argentina. Para otros casos se proponen identificaciones a confrontar (cf.), sugiriendo el epíteto específico más probable de acuerdo con su distribución en la zona según las bases de datos consultadas (p.e. Alstroemeria cf. patagonica Phil.). Una situación especial pudo hallarse respecto a las distintas especies del género Berberis L., ya que MC se refiere a ellas como Berberis spp. o "todos los Berberis" al hacer referencia a su nombre vulgar. Este habría coleccionado varias de las especies de este género que crecen en la provincia de Santa Cruz, aunque sin embargo no se pudieron hallar estos ejemplares ni en los herbarios ni en las bases de datos consultadas. Por ello decidimos indicar las especies del género Berberis señaladas para el norte de la Patagonia en las libretas de campo por MC correspondientes a otras de sus campañas precedido de "cf.", previa confirmación de su presencia en la provincia de Santa Cruz según Zuloaga et al. (2019). Asimismo, al consultar los ejemplares vegetales coleccionados por MC en la provincia de Santa Cruz bajo su numeración personal en el Herbario de Plantas Vasculares del IBONE (CTES), se hallaron en sus etiquetas novedosas identificaciones botánicas infragenéricas producto del trabajo efectuado por taxónomos desde que aquél allí los depositara (determinaciones de A. L. Cabrera y G. Bernardello, entre otros).

\section{Integración de los datos inéditos con los compilados en la bibliografía}

Se ponen en valor un total de 163 datos etnobotánicos de la etnobotánica del pueblo Aonik'enk procedentes de los registros de campo de Raúl Martínez Crovetto, así como 105 provenientes de las fuentes secundarias publicadas consultadas. En total se pudieron identificar 244 datos etnobotánicos netos (i.e. no repetidos) sobre este pueblo referidos a 117 taxa botánicos. De estos últimos, la mayoría 94 $(79,7 \%)$ pudo ser identificado hasta el nivel específico, $19(16,1 \%)$ hasta género y $2(1,7 \%)$ hasta familia botánica, restando $3(2,5 \%)$ de ellos sin determinar. En la Tabla 1 se describe cada uno de los usos recopilados indicando parte usada, forma de preparación y consumo o administración, siempre que fue posible, acerca de cada taxón vegetal referido por su nombre botánico actualizado, nombre referido en las fuentes, número de herbario y nombre vulgar referido. Solo se cita la fuente en caso de que esta aluda a una cita bibliográfica, caso contrario se asume que proviene de los datos inéditos de MC.

La mayor parte de los datos corresponden a usos alimenticios $(89 ; 36,5 \%)$ y medicinales $(81 ; 33,2 \%)$. En mucha menor proporción -menos del $4 \%$ - se han registrado fumatorios (9 datos), datos vinculados a creencias (9), utensilios y combustibles ( 7 cada uno); música (6), juegos (5) y usos vinculados con los aperos del caballo (5). En el gráfico de la Fig. 2 se representa la participación relativa de todas las categorías de usos registradas. Dentro de los usos alimenticios se destaca el consumo de frutos, hojas y órganos subterráneos crudos $(30 \%, 27$ datos), seguido por los hervidos y los relativos a la preparación de bebidas $(13,5 \%, 12$ datos cada uno), asados (9\%, 8 datos) y asociados a la preparación de harinas y panificados $(5.6 \%$, 5 datos). Los usos medicinales más referidos son los destinados a tratar contusiones con 14 datos (antiinflamatorios y hematomas o "golpe interno"), gastralgias (10 datos), cefalalgias y heridas (vulnerarios) (5 datos cada uno) y dolores reumáticos (4 datos).

Las plantas con mayor cantidad de datos etnobotánicos son los "calafates" (Berberis spp.) con 19 tipos de datos asignados, supuestamente, a cualquiera de las cuatro especies botánicas involucradas, seguido por Schinus marchandii o "molle" (con 8 usos), Azorella trifurcata y Bolax gummifera (con 6) y luego por Acantholippia seryphioides, Adesmia boronoides y Ribes magallanicum (con 5 datos cada uno).

De los 163 datos etnobotánicos Aonik'enk provenientes de los archivos inéditos de MC, solo 23 coinciden con los registros bibliográficos compilados, por lo que 140 de ellos resultan absolutamente novedosos para la etnobotánica de este pueblo. 
Tabla 1. Datos etnobotánicos inéditos y bibliográficos para el pueblo Aonik'enk. Abreviaturas: BU, bulbos. CFR, cuerpos fructíferos. CO, corteza. DU, duramen. FL, flores. FR, frutos. GL, glebas. HO, hojas. PA, parte aérea. RA, raíz. RI, rizomas. SE, semillas. TA, tallos. TAH, tallos y hojas. TO, toda la planta. TU, tubérculos. Dec., decocción. Ext., aplicación externa. Inf., infusión. Ing., ingerida.

\begin{tabular}{|c|c|c|}
\hline $\begin{array}{l}\text { Taxa actualizados (taxón hallado en la } \\
\text { fuente y } n^{\circ} \text { de herbario) }\end{array}$ & $\begin{array}{l}\text { Nombre } \\
\text { Aonik'enk }\end{array}$ & Usos o significados inéditos (sin cita) y publicados (citados) \\
\hline \multicolumn{3}{|l|}{ FUNGI } \\
\hline \multicolumn{3}{|l|}{ AGARICACEAE } \\
\hline Agaricus sp. & Ájchen jaát & $\begin{array}{l}\text { No se comen ni se tocan pues se considera la comida de "ájchen" o } \\
\text { "espíritu de la piedra" de carácter nefasto }\end{array}$ \\
\hline \multicolumn{3}{|l|}{ CYTTARIACEAE } \\
\hline $\begin{array}{l}\text { Cyttaria darwini Berk. } \\
\text { Cyttaria hookeri Berk. }\end{array}$ & Cháun & $\begin{array}{l}\text { Sus CFR se comen. Martinič (1995) y Musters (1964) también citan } \\
\text { este uso. }\end{array}$ \\
\hline \multicolumn{3}{|l|}{ FISTULINACEAE } \\
\hline Fistulina hepatica (Schaeff.) With. & Châte & Sus CFR? se consumen hervidos. \\
\hline \multicolumn{3}{|l|}{ LYCOPERDACEAE } \\
\hline Calvatia caelata (Bull.) Morgan & & $\begin{array}{l}\text { Según Martinič (1995) sus CFR se consumen inmaduros, cuando } \\
\text { tienen la consistencia y el aspecto del quesillo. }\end{array}$ \\
\hline $\begin{array}{l}\text { Calvatia lilacina (Mont. \& Berk.) Henn } \\
\text { Calvatia sp. }\end{array}$ & $\begin{array}{l}\text { Ájchen } \\
\text { késhuen }\end{array}$ & $\begin{array}{l}\text { Su GL se usa como cicatrizante. Se considera que el "espíritu de la } \\
\text { piedra" ("ajchen") lo utiliza para pintar las piedras. }\end{array}$ \\
\hline \multicolumn{3}{|l|}{ FANEROGAMAE } \\
\hline \multicolumn{3}{|l|}{ ALSTROEMERIACEAE } \\
\hline $\begin{array}{l}\text { Alstroemeria patagonica } \text { Phil. } \\
\text { (Alstroemeria sp., P. 136) }\end{array}$ & Saj & $\begin{array}{l}\text { Sus RI se comen. Idem Embon (1950) citado por Ciampagna \& } \\
\text { Capparelli (2012) }\end{array}$ \\
\hline cf. Luzuriaga spp. & - & Con sus TA se hacen peines (Martinič, 1995). \\
\hline \multicolumn{3}{|l|}{ AMARYLLIDACEAE } \\
\hline $\begin{array}{l}\text { Tristagma ameghinoi (Speg.) Speg. } \\
\text { Tristagma patagonicum (Baker) Traub }\end{array}$ & Áchame & Sus BU se consumen crudos y asados \\
\hline \multicolumn{3}{|l|}{ ANACARDIACEAE } \\
\hline $\begin{array}{l}\text { Schinus marchandii F.A. Barkley } \\
\text { (Schinus } \text { sp., P. 144) }\end{array}$ & Molle, tel & $\begin{array}{l}\text { Sus FR se comen frescos y con su macerado se prepara una bebida } \\
\text { refrescante. Con su TA se fabrica un cordófono ("kôlo"), pipas ("golke" } \\
\text { y "ánwe") y un palo cavador. Escalada (1949) cita también este último } \\
\text { uso. El uso de su RE como masticatorio también es citado por Outes } \\
\text { (1905). Su DU molido con grasa se usaba como pintura facial roja. }\end{array}$ \\
\hline \multicolumn{3}{|l|}{ APIACEAE } \\
\hline ¿? (Ejemplar de herbario “P-48”) & $\begin{array}{l}\text { Tesmen, neneo } \\
\text { chico }\end{array}$ & Dec. Ext. como antialopécico. \\
\hline Apium australe Thouars & Gá lal & $\begin{array}{l}\text { Sus HO se comen crudas o hervidas. Lista (2006) y Schmid (1964) } \\
\text { citan estos mismos usos. }\end{array}$ \\
\hline Apium graveolens $\mathrm{L}$. & Gá lal & $\begin{array}{l}\text { Idem anterior. Además, Onelli (1904) cita su empleo como purgante } \\
\text { drástico junto a Erythranthe bridgesii. }\end{array}$ \\
\hline $\begin{array}{l}\text { Azorella prolifera (Cav.) G.M. Plunkett \& } \\
\text { A.N. Nicolas (=Mulinum spinosum, P. 63) }\end{array}$ & Tesmen & $\begin{array}{l}\text { Dec. de TO Ext. como antialopécico. Su Dec. se emplea "para curar } \\
\text { enfermedades internas del caballo". }\end{array}$ \\
\hline Azorella selago Hook. f. & - & $\begin{array}{l}\text { Su resina gomosa es eficaz contra heridas expuestas (Martinič, 1995). } \\
\text { Spegazzini (1884) se referiría a esta especie cuando indica el uso de la } \\
\text { goma de Azorella diapensioides A. Gray con grasa para "empastar" o } \\
\text { diluir tintes minerales (ya que dicho taxón solo crece en la provincia } \\
\text { de Jujuy). }\end{array}$ \\
\hline $\begin{array}{l}\text { Azorella trifurcata (Gaertn.) Pers. } \\
\text { (Azorella spp., P. 92, P. 135) }\end{array}$ & $\begin{array}{l}\text { Tésme, Tesh, } \\
\text { tish, tus }\end{array}$ & $\begin{array}{l}\text { Sus RA se consumían crudas, cocidas o asadas al rescoldo --idem } \\
\text { según Fitz Roy (1839)-. También se empleaba como leña y en dec. Ing. } \\
\text { contra gastralgias. }\end{array}$ \\
\hline Bolax gummifera (Lam.) Spreng. & Tẽrsh & $\begin{array}{l}\text { Idem anterior. Además Spegazzini (1884) y Martinič (1995) citan que } \\
\text { su resina o "savia" les resultaba vulnerario. }\end{array}$ \\
\hline
\end{tabular}


Tabla 1. (Continuación).

\begin{tabular}{|c|c|c|}
\hline $\begin{array}{l}\text { Taxa actualizados (taxón hallado en la } \\
\text { fuente } y \mathrm{n}^{\circ} \text { de herbario) }\end{array}$ & $\begin{array}{l}\text { Nombre } \\
\text { Aonik'enk }\end{array}$ & Usos o significados inéditos (sin cita) y publicados (citados) \\
\hline \multicolumn{3}{|l|}{ AQUIFOLIACEAE } \\
\hline Ilex paraguariensis A. St.-Hil. & Áashken & $\begin{array}{l}\text { Sus TAH molidos se consume como mate y masticatorio (con azúcar y } \\
\text { agua) -idem cita Lista (1975)-. Según Musters (1964), dicha molienda } \\
\text { también se fumaba mezclado con una hierba que obtenían de los } \\
\text { araucanos, como sucedáneo del tabaco }\end{array}$ \\
\hline \multicolumn{3}{|l|}{ ASTERACEAE } \\
\hline Baccharis sp. & Sheř & Sus TA se emplean como leña. \\
\hline $\begin{array}{l}\text { Chiliotrichum diffusum (G. Forst.) } \\
\text { Kuntze }\end{array}$ & Romerillo & $\begin{array}{l}\text { Según Martinič (1995) sus flores se emplean contra oftalmias ("para } \\
\text { aclarar la visión"). }\end{array}$ \\
\hline Chuquiraga avellanedae Lorentz & k'alche & $\begin{array}{l}\text { Según Spegazzini (1884) es planta "de una amargura insoportable y } \\
\text { que muchos tienen la costumbre de mascar" }\end{array}$ \\
\hline $\begin{array}{l}\text { Hypochaeris incana (Hook. \& Arn.) } \\
\text { Macloskie (P. 12) }\end{array}$ & Élue jat, kôr & La Dec. de su PA Ing. como hepático digestivo. \\
\hline $\begin{array}{l}\text { Lepidophyllum cupressiforme (Lam.) } \\
\text { Cass (Lepidophyllum sp.) }\end{array}$ & Sheř & Su TA se usa como leña. \\
\hline Matricaria discoidea DC. & Guéut yáuch & $\begin{array}{l}\text { Dec. Ing. como estomáquico. TO se emplea seca y molida como } \\
\text { fumatorio, uso del cual deriva su nombre vulgar. }\end{array}$ \\
\hline
\end{tabular}

Senecio neaei DC. (Senecio sp., P. 79,

P. 150)

Senecio patagonicus Hook. \& Arn.

(Senecio sp., P. 14, P. 114)

Senecio trifurcatus (G. Forst.) Less.

(Senecio sp., P. 4)

Taraxacum sp. (P. 90)

Taraxacum gilliesii Hook. \& Arn.

Dec. en fricciones contra reumatismo e Ing. contra golpes internos y trastornos hepáticos. Su PA se incinera en un ritual precautorio para ahuyentar con su humo al "espíritu malo".

Taraxacum officinale F.H. Wigg. (P. 82)

Margo, kôr

Sus HO se comen crudas en ensaladas o hervidas

Idem anterior

BERBERIDACEAE

Berberis darwinii Hook.

Berberis empetrifolia Lam.

Berberis ilicifolia L. f.

Berberis microphylla $\mathrm{G}$. Forst.
Idem anterior. Lista (2006) y Martinič (1995) citan este uso añadiendo que hasta sus RA también eran consumidas.
Berberis spp.

Chorch
Sus FR se consumen frescos y elaboran con ellos una bebida -Idem citan Outes (1905), Martinič (1995), Lista (2006) y Spegazzini (1884)-

Chorch . Lista (1975) y Martinič (1995) citan que la bebida ("wachakai") se preparaba con sus FR macerados en aguardiente o fermentados en agua hacia finales del siglo XIX.

Sus FR macerados que rinden una tintura roja y la dec. de su RA picada que brinda un color amarillo, se usan para colorear lana. Su TA trozados se emplean como atemperante del tabaco -idem citan Hesketh-Prichard (1902), Martinič (1995) y Childs (1997) [1936]-. Según los primeros dos autores y Roncaglia (1884) citado por Ciampagna \& Capparelli (2012), con sus TA hacían pipas de madera. La Dec. de su RA Ing. se usaba contra dolores de vejiga y según Fitz Roy (1839) como preventivo en general. Según este último autor, con sus TA hacían pinceles de madera para pintar cueros, los cuales consistían en palos rústicos aguzados en las puntas. También confeccionaban un cordófono en forma de arco ("violín") de 45-60 cm de largo. Consistía en un trozo de su tronco despojado de corteza y pulido que era curvado, entre cuyas puntas se insertaba un haz de $15-20$ cuerdas de crin de caballo. Con su madera también se confeccionaban estacas, astiles de flechas, estribos y la base de raspadores en los que se insertaban trozos de vidrio amarrados con un tiento (Martinič, 1995). Según este autor, las mujeres se pintaban la cara con el zumo de sus FR -azul intenso- en la creencia de que así blanquearían su cutis. Con su madera también hacían fichas de unos $15 \mathrm{~cm}$ de largo y punta aguzada para sus juegos de naipes (Martinič, 1995). Esta planta posee gran significación en su cosmología mítica y social. Alberga al espíritu "ájchen" de carácter patogénico, el cual infundía temor en las noches a mujeres y niños (Martinič, 1995). 
Tabla 1. (Continuación).

\begin{tabular}{|c|c|c|}
\hline $\begin{array}{l}\text { Taxa actualizados (taxón hallado en la } \\
\text { fuente y } n^{0} \text { de herbario) }\end{array}$ & $\begin{array}{l}\text { Nombre } \\
\text { Aonik'enk }\end{array}$ & Usos o significados inéditos (sin cita) y publicados (citados) \\
\hline \multicolumn{3}{|l|}{ BRASSICACEAE } \\
\hline Brassica rapa $\mathrm{L}$. & Nabo & $\begin{array}{l}\text { Sus TA subterráneos son adquiridos en comercios con fines alimenticios } \\
\text { según Martinič (1995) }\end{array}$ \\
\hline $\begin{array}{l}\text { Descurainia antarctica (E. Fourn.) O.E. } \\
\text { Schulz }\end{array}$ & Kálken & Sus SE se recolectan con fines alimenticios según Fitz Roy (1839) \\
\hline \multicolumn{3}{|l|}{ CACTACEAE } \\
\hline ¿? & Mo, tunas & Sus FR se consumen asados. \\
\hline $\begin{array}{l}\text { Maihueniopsis darwinii (Hensl.) F. Ritter } \\
\text { var. darwinii (=Opuntia darwinii) }\end{array}$ & Mo & Sus FR se consumen asados. \\
\hline \multicolumn{3}{|l|}{ CALYCERACEAE } \\
\hline $\begin{array}{l}\text { Gamocarpha australis (Decne.) S.S. } \\
\text { Denham \& Pozner (=Boopis australis, P. } \\
62, \text { P. 85) }\end{array}$ & Ishte & Sus RA se consumen como alimento. \\
\hline \multicolumn{3}{|l|}{ CAPRIFOLIACEAE } \\
\hline $\begin{array}{l}\text { Valeriana carnosa Sm. (Valeriana } \mathrm{sp} ., \mathrm{P} . \\
\text { 77) (CTES) }\end{array}$ & Kámpter jat & Dec. de RA Ing. contra trastornos hepáticos. \\
\hline \multicolumn{3}{|l|}{ CARYOPHYLLACEAE } \\
\hline $\begin{array}{l}\text { Colobanthus cf. lycopodiodes Griseb. } \\
\text { (Colobanthus sp., P. 53) }\end{array}$ & Tápel, musgo & TO de manera tópica como antiinflamatorio. \\
\hline \multicolumn{3}{|l|}{ CELASTRACEAE } \\
\hline Maytenus boaria Molina & Maitén & $\begin{array}{l}\text { Según Onelli (1904) sus HO se emplean como febrífugo, las que } \\
\text { obtienen de araucanos de Rio Negro y de Chile. }\end{array}$ \\
\hline \multicolumn{3}{|l|}{ CHENOPODIACEAE } \\
\hline Atriplex sp. (P. 13) & Iókson & Dec. de TAH? Ing. se usa contra gastralgias y como purgante \\
\hline Chenopodium quinoa Willd. & Quinoa? & Sus SE tostadas y luego molidas entre dos piedras son comestibles. \\
\hline \multicolumn{3}{|l|}{ CYPERACEAE } \\
\hline $\begin{array}{l}\text { Schoenoplectus californicus (C.A. Mey.) } \\
\text { Soják (=Scirpus californicus) }\end{array}$ & Kórpe, Óompe & $\begin{array}{l}\text { Los RI se consumen crudos raspándoles la corteza, mientras que sus } \\
\text { TA se usan en confección de bastos de monturas. }\end{array}$ \\
\hline \multicolumn{3}{|l|}{ EPHEDRACEAE } \\
\hline Ephedra sp. (P. 22) & Tish & Sus FR se comen frescos -idem cita Lista (2006)-. \\
\hline \multicolumn{3}{|l|}{ ERICACEAE } \\
\hline Empetrum rubrum Vahl ex Willd. & Pélko & Sus FR se comen fresco -idem cita Martinič (1995)-. \\
\hline $\begin{array}{l}\text { Gaultheria mucronata } \text { (L. f.) Hook. \& } \\
\text { Arn. (=Pernettya mucronata) } \\
\text { Gaultheria pumila (L. f.) D.J. Middleton } \\
\text { (=Pernettya pumila) }\end{array}$ & - & Sus FR se comen fresco -idem cita Martinič (1995)-. \\
\hline \multicolumn{3}{|l|}{ EUPHORBIACEAE } \\
\hline Euphorbia portulacoides L. & $\begin{array}{l}\text { Ióksön, } \\
\text { Pichoga }\end{array}$ & Dec. de TAH Ing. como estomáquico. \\
\hline \multicolumn{3}{|l|}{ FABACEAE } \\
\hline Adesmia boronioides Hook. f. (P. 15) & $\begin{array}{l}\text { Kárto, Sher } \\
\text { cha, Paramela }\end{array}$ & $\begin{array}{l}\text { Dec. de TAH con azúcar y café o bien agregando las HO en el mate } \\
\text { es Ing. como estomáquico, expectorante, antitusivo, antiinflamatorio y } \\
\text { contra gastralgias. }\end{array}$ \\
\hline Adesmia spp. & Sher & Dec. Ing. como antiinflamatorio. \\
\hline
\end{tabular}




\section{G. F. SCARPA ET AL. Etnobotánica Aonik'enk (Tehuelches de Santa Cruz) inédita}

Tabla 1. (Continuación).

\begin{tabular}{|c|c|c|}
\hline $\begin{array}{l}\text { Taxa actualizados (taxón hallado en la } \\
\text { fuente y } \mathbf{n}^{\circ} \text { de herbario) }\end{array}$ & $\begin{array}{l}\text { Nombre } \\
\text { Aonik'enk }\end{array}$ & Usos o significados inéditos (sin cita) y publicados (citados) \\
\hline $\begin{array}{l}\text { Anarthrophyllum rigidum (Gillies ex } \\
\text { Hook. \& Arn.) Hieron. (P. 111) }\end{array}$ & $\begin{array}{l}\text { Chélkot, } \\
\text { chílkot, kar }\end{array}$ & $\begin{array}{l}\text { Sus FL se consumen como piscolabis y sialogogo. Sus TAH? se } \\
\text { emplean como cercos, mientras que su Dec. Ing. como tónico. }\end{array}$ \\
\hline $\begin{array}{l}\text { Glycyrrhiza astragalina Gillies ex Hook. } \\
\text { \& Arn. }\end{array}$ & Orozúz & Según Onelli (1904) la Dec. de su RA Ing. contra resfríos y bronquitis. \\
\hline Phaseolus sp. & Porotos & Martinič (1995) cita su empleo como comestible. \\
\hline $\begin{array}{l}\text { Prosopis alpataco Phil. } \\
\text { P. denudans Benth. var. denudans } \\
\text { (=Prosopis } \mathrm{sp} .) \\
\text { P. denudans Benth. var. patagonica } \\
\text { (Speg.) Burkart (=Prosopis patagonica) }\end{array}$ & $\begin{array}{l}\text { Algarrobo } \\
\text { Chen }\end{array}$ & $\begin{array}{l}\text { Sus TA se usan como leña. Según Musters (1964) y Outes (1905) } \\
\text { comían una especie de torta elaborada con sus FR machacados y } \\
\text { empastados con agua. }\end{array}$ \\
\hline Vicia faba $\mathrm{L}$. & Awásh & Sus SE se consumen como alimento. \\
\hline \multicolumn{3}{|l|}{ GERANIACEAE } \\
\hline Erodium cicutarium (L.) L’Hér. ex Aiton & Guels & $\begin{array}{l}\text { Dec. TAH? se Ing. contra "golpes internos" y de manera tópica se usa } \\
\text { como vulnerario y analgésico. }\end{array}$ \\
\hline \multicolumn{3}{|l|}{ GROSSULARIACEAE } \\
\hline Ribes magellanicum Poir. & Kóorr & $\begin{array}{l}\text { Sus FR se consumen frescos -idem cita Martinič (1995)-. Su Dec. se } \\
\text { Ing. como depurativo sanguíneo y se aplica de manera tópica contra } \\
\text { reumatismo. Su PA se quema en ritual precautorio para ahuyentar a } \\
\text { espíritus patógenos. Según Martinič (1995) la Dec. de HO y CO se } \\
\text { emplea contra gastralgias. }\end{array}$ \\
\hline \multicolumn{3}{|l|}{ GUNNERACEAE } \\
\hline Gunnera sp. & - & Según Musters (1964) se emplea como alimenticia. \\
\hline $\begin{array}{l}\text { Gunnera tinctoria (Molina) Mirb. var. } \\
\text { tinctoria }\end{array}$ & - & $\begin{array}{l}\text { Según Lista (2006) sus pecíolos se comen, mientras que su Dec. se Ing. } \\
\text { como diurético. }\end{array}$ \\
\hline \multicolumn{3}{|l|}{ IRIDACEAE } \\
\hline $\begin{array}{l}\text { Olsynium junceum (E. Mey. ex C. Presl) } \\
\text { Goldblatt (=Sisyrinchium junceum) }\end{array}$ & $\underset{\text { jat }}{\text { Kel jat, Élue }}$ & $\begin{array}{l}\text { Sus FL crudas se comen y con su macerado en azúcar se prepara una } \\
\text { bebida refrescante. }\end{array}$ \\
\hline \multicolumn{3}{|l|}{ JUNCACEAE } \\
\hline Juncus aff. balticus Willd. (P. 54, P. 106) & Öte, chéep & $\begin{array}{l}\text { Sus TA se usan para ataduras y trenzados. Idem cita Fitz Roy (1839), } \\
\text { indicando que se trataba de cestos o "canastitos tipo fueguino". }\end{array}$ \\
\hline $\begin{array}{l}\text { cf. Marsippospermum grandiflorum (L. } \\
\text { f.) Hook. f. }\end{array}$ & - & $\begin{array}{l}\text { Idem anterior según Fitz Roy (1839), aunque indica que tales } \\
\text { recipientes se usaban para beber. }\end{array}$ \\
\hline \multicolumn{3}{|l|}{ LAMIACEAE } \\
\hline Mentha sp. & Galál léen & Inf. de sus HO Ing. contra gastralgias. \\
\hline $\begin{array}{l}\text { Mentha piperita } \mathrm{L} . \\
\text { Mentha spicata } \mathrm{L} . \mathrm{var} \text {. rotundifolia } \mathrm{L} . \\
\text { (Mentha spicata, P. 110) }\end{array}$ & Galal léen & $\begin{array}{l}\text { Según Onelli (1904) con estas plantas y "tomillo" se elaboraba una } \\
\text { tisana Ing. como sudorífico. }\end{array}$ \\
\hline \multicolumn{3}{|l|}{ MISODENDRACEAE } \\
\hline Misodendrum cf. punctulatum DC. & - & Según Martinič (1995: 301) se usaba como antimiálgico. \\
\hline \multicolumn{3}{|l|}{ MONIMIACEAE } \\
\hline Peumus boldus Molina & Boldo & $\begin{array}{l}\text { Según Onelli (1904) la Dec. de sus HO se emplea como hepático } \\
\text { digestivo, siendo una de las plantas que obtenían por intercambio con } \\
\text { los "araucanos". }\end{array}$ \\
\hline \multicolumn{3}{|l|}{ MYRTACEAE } \\
\hline Myrteola nummularia (Poir.) O. Berg. & - & Lista (2006) indica que sus FR se consumen frescos. \\
\hline
\end{tabular}


Tabla 1. (Continuación).

\begin{tabular}{|c|c|c|}
\hline $\begin{array}{l}\text { Taxa actualizados (taxón hallado en la } \\
\text { fuente y } n^{0} \text { de herbario) }\end{array}$ & $\begin{array}{l}\text { Nombre } \\
\text { Aonik'enk }\end{array}$ & Usos o significados inéditos (sin cita) y publicados (citados) \\
\hline \multicolumn{3}{|l|}{ NOTHOFAGACEAE } \\
\hline Nothofagus antarctica (G. Forst.) Oerst. & - & $\begin{array}{l}\text { Según Hesketh-Prichard (1902) y Martinič }(1995) \text { con su madera } \\
\text { confeccionaban pipas cuyo cuerpo era de } 6 \text { x } 3 \mathrm{~cm} \text { y el hornillo } \\
\text { redondo de } 1,5-2,5 \mathrm{~cm} \text { de alto con boquilla de cobre o bronce. Según } \\
\text { Martinič (1995) los parantes de sus toldos eran confeccionados con su } \\
\text { madera, los que eran conservados en sus traslados. Lehmann-Nitsche } \\
\text { (1908) cita que son su madera se confeccionaba un cordófono o "arco } \\
\text { musical" (especie de violín). }\end{array}$ \\
\hline Nothofagus dombeyi (Mirb.) Oerst. & - & $\begin{array}{l}\text { Según Martinič (1995) con su madera se confeccionaban los estribos de } \\
\text { sus monturas, los cuales eran triangulares y redondeados en sus puntas. }\end{array}$ \\
\hline $\begin{array}{l}\text { Nothofagus pumilio (Poepp. \& Endl.) } \\
\text { Krasser }\end{array}$ & - & Según Martinič (1995) con su madera hacían los parantes de sus toldos. \\
\hline Nothofagus spp. & - & $\begin{array}{l}\text { Martinič (1995) cita que con su madera se hacían arcos y astiles de } \\
\text { flechas. El mismo autor señala que con ella también confeccionaban un } \\
\text { tambor en forma de vasija semiesférica, cuya boca era cubierta con un } \\
\text { cuero cosido a manera de parche. }\end{array}$ \\
\hline \multicolumn{3}{|l|}{ PHRYMACEAE } \\
\hline $\begin{array}{l}\text { Erythranthe bridgesii (Benth.) G.L. } \\
\text { Nesom }\end{array}$ & Berro silvestre & $\begin{array}{l}\text { Onelli (1904) señala que junto a Apium australe preparaban un remedio } \\
\text { purgante drástico. }\end{array}$ \\
\hline \multicolumn{3}{|l|}{ PLUMBAGINACEAE } \\
\hline $\begin{array}{l}\text { Limonium brasiliense (Boiss.) Kuntze } \\
\text { (Limonium sp., P. } 32 \text { ) }\end{array}$ & Guáikoro & $\begin{array}{l}\text { Dec. de RA era Ing. contra gastralgias. Martinič (1995) también cita su } \\
\text { uso como antiulceroso, antidisentérico y purgante. }\end{array}$ \\
\hline \multicolumn{3}{|l|}{ POACEAE } \\
\hline $\begin{array}{l}\text { Cortaderia araucana } \text { Stapf } \\
\text { Cortaderia selloana (Schult. \& Schult. f.) } \\
\text { Asch. \& Graebn. }\end{array}$ & Télsen & $\begin{array}{l}\text { Con sus cañas floríferas confeccionaban un aerófono o flauta } \\
\text { denominada "kôlo". }\end{array}$ \\
\hline $\begin{array}{l}\text { cf. Elymus magellanicus (E. Desv.) A. } \\
\text { Löve (=Elymus glaucescens Seberg, P. 36) }\end{array}$ & Shalq & $\begin{array}{l}\text { Fitz Roy (1839) cita que sus TA se empleaban en cestería para hacer } \\
\text { trenzados en forma de "canastitos del tipo fueguino". }\end{array}$ \\
\hline Chusquea culeou E. Desv. & - & $\begin{array}{l}\text { Lista (2006) y Outes (1905) señalan que con sus cañas confeccionaban } \\
\text { estribos. }\end{array}$ \\
\hline Chusquea spp. & - & $\begin{array}{l}\text { Martinič (1995) cita que la "caña colihue" se utilizaba para confeccionar } \\
\text { la base de raspadores (ya descriptos). También fabricaban con sus cañas } \\
\text { lanzas a las cuales les añadían una punta de hierro (Martinič, 1995). }\end{array}$ \\
\hline
\end{tabular}

Hordeum pubiflorum Hook. f. (P. 25; P. 30) Guels, eskel, k'or Su PA era empleaba como combustible.

\begin{tabular}{|c|c|c|}
\hline Oryza sativa $\mathrm{L}$. & Aros & Martinič (1995) indica que se consumía como alimento. \\
\hline $\begin{array}{l}\text { Pappostipa ibarii (Phil.) Romasch. } \\
\text { (=Stipa ibari Phil., P. 17) } \\
\text { Stipa sp. (P. 60; P. 70) (CTES) }\end{array}$ & Guels & $\begin{array}{l}\text { La Dec. de sus TAH? era Ing. contra "golpes internos" y aplicado de } \\
\text { manera tópica como vulnerario. }\end{array}$ \\
\hline Saccharum officinarum $\mathrm{L}$. & & Martinič (1995) indica que consumían azúcar como alimento. \\
\hline Triticum aestivum $\mathrm{L}$. & & $\begin{array}{l}\text { Con su harina preparaban panificados varios -Martinič (1995) cita el } \\
\text { mismo uso-. }\end{array}$ \\
\hline Zea mays $\mathrm{L}$. & Pio jat & $\begin{array}{l}\text { Sus SE se consumen como alimento. Outes (1905) señala que con la } \\
\text { dec. de sus SE se elaboraba una bebida. }\end{array}$ \\
\hline \multicolumn{3}{|l|}{ POLYGONACEAE } \\
\hline Rumex sp. (P. 97) & Gálal & Sus HO se consumen hervidas como verdura y en almíbar. \\
\hline Rumex sp. & Gál & $\begin{array}{l}\text { Lista (2006), Fitz Roy (1839) y Schmid (1964) señalan que su RA } \\
\text { asada era consumida como alimento. }\end{array}$ \\
\hline Rumex acetosella L. (P. 29) (CTES) & K'âpenk kôř & $\begin{array}{l}\text { Sus HO se consumen crudas o hervidas. Lista (2006) y Schmid (1964) } \\
\text { citan el mismo uso. }\end{array}$ \\
\hline \multicolumn{3}{|l|}{ PROTEACEAE } \\
\hline $\begin{array}{l}\text { Embothrium coccineum J.R. Forst. \& G. } \\
\text { Forst. }\end{array}$ & - & $\begin{array}{l}\text { Con la madera de su TA confeccionaban una pipa como la ya descripta, } \\
\text { además de espuelas, estribos y bocados de caballos (Martinič, 1995). }\end{array}$ \\
\hline
\end{tabular}




\section{G. F. SCARPA ET AL. Etnobotánica Aonik'enk (Tehuelches de Santa Cruz) inédita}

Tabla 1. (Continuación).

\begin{tabular}{|c|c|c|}
\hline $\begin{array}{l}\text { Taxa actualizados (taxón hallado en la } \\
\text { fuente y } n^{0} \text { de herbario) }\end{array}$ & $\begin{array}{c}\text { Nombre } \\
\text { Aonik'enk }\end{array}$ & Usos o significados inéditos (sin cita) y publicados (citados) \\
\hline \multicolumn{3}{|l|}{ ROSACEAE } \\
\hline $\begin{array}{l}\text { Acaena confertissima } \text { Bitter } \\
\text { Acaena integerrima Gillies ex Hook. \& Arn } \\
\text { Acaena magellanica } \text { (Lam.) Vahl } \\
\text { Acaena ovalifolia } \text { Ruiz \& Pav } \\
\text { Acaena sericea J. Jacq. }\end{array}$ & Táparr & $\begin{array}{l}\text { Sus FR eran utilizados como proyectiles adherentes por los niños a } \\
\text { manera de juego. }\end{array}$ \\
\hline $\begin{array}{l}\text { Acaena ovalifolia } \text { Ruiz \& Pav. } \\
\text { Acaena pinnatifida } \text { Ruiz \& Pav. } \\
\text { Acaena platyacantha } \text { Speg. } \\
\text { Acaena sericea J. Jacq. }\end{array}$ & Táparr, & $\begin{array}{l}\text { La Dec. de TO se Ing. como antiinflamatorio y en lavajes contra } \\
\text { cefalalgias. La Dec. de su PA era Ing. contra gastralgias. }\end{array}$ \\
\hline $\begin{array}{l}\text { Potentilla chiloensis }(\mathrm{L} .) \text { Mabb. } \\
\text { (=Fragaria chiloensis) }\end{array}$ & Cháut & Sus FR se consumen frescos. \\
\hline Rubus geoides $\mathrm{Sm}$. & & Sus FR se consumen frescos (Martinič, 1995). \\
\hline \multicolumn{3}{|l|}{ SCHOEPFIACEAE } \\
\hline $\begin{array}{l}\text { Arjona patagonica Hombr. \& Jacq. ex } \\
\text { Decne (Arjona sp., P. 132) (CTES) }\end{array}$ & Saj & Sus TU se consumen crudos -Martinič (1995) también cita este uso-. \\
\hline $\begin{array}{l}\text { Arjona tuberosa Cav. (Arjona sp., P. 145) } \\
\text { (CTES) }\end{array}$ & Saj & Sus TU se consumen crudos -Spegazzini (1884) también cita este uso-. \\
\hline \multicolumn{3}{|l|}{ SOLANACEAE } \\
\hline Fabiana imbricata Ruiz \& Pav. & Piche & $\begin{array}{l}\text { Según Onelli (1904) se emplea como diurético. Es una de las plantas } \\
\text { que, desde Neuquén, consiguen por intercambio. }\end{array}$ \\
\hline $\begin{array}{l}\text { Lycium ameghinoi Speg. (sin datos, P. } \\
\text { 141) (CTES) }\end{array}$ & $\begin{array}{l}\text { Táparr, San } \\
\text { Benito }\end{array}$ & Sus FR se consumen frescos. \\
\hline Nicotiana tabacum L. & Yáuch(e) & $\begin{array}{l}\text { Sus HO como fumatorio (cigarrillos, pipas) y mascatorio. Esto mismo } \\
\text { es citado por Hesketh-Prichard (1902), Martinič (1995) y Childs } \\
(1997[1936]) \text {. }\end{array}$ \\
\hline Solanum tuberosum L. & Ashpal & Sus TU se comen hervidos -Martinič (1995) también cita este uso-. \\
\hline \multicolumn{3}{|l|}{ TROPAEOLACEAE } \\
\hline Tropaeolum patagonicum Speg. & Chale & $\begin{array}{l}\text { Sus RA se consumen crudas, asadas al rescoldo y hervidas en puchero. } \\
\text { Los mismos usos citan Lista (2006), Fitz Roy (1839) y Schmid (1964). }\end{array}$ \\
\hline \multicolumn{3}{|l|}{ VERBENACEAE } \\
\hline $\begin{array}{l}\text { Acantholippia seriphioides (A. Gray) } \\
\text { Moldenke }\end{array}$ & $\begin{array}{l}\text { Keléen, Té } \\
\text { pampa }\end{array}$ & $\begin{array}{l}\text { Con la Inf. de sus TAH se elabora una bebida estimulante de color } \\
\text { rojizo - citado también por Martinič (1995)-. Este último señala que la } \\
\text { Dec. Ing. de su PA se empleaba como antibiótico, antiinflamatorio y } \\
\text { antiespasmódico. Onelli (1904) en cambio cita que su tisana era usada } \\
\text { como sudorífico. }\end{array}$ \\
\hline $\begin{array}{l}\text { Mulguraea tridens (Lag.) N. O’Leary \& } \\
\text { P. Peralta (=Verbena tridens, P. 24) }\end{array}$ & $\begin{array}{l}\text { Mata negra, } \\
\text { k'ake, shake }\end{array}$ & $\begin{array}{l}\text { Sus RA se usaban como dientes de un peine -también citado por } \\
\text { Martinič (1995)-. Sus TAH se emplean como leña para asar y como } \\
\text { cercos, uso también citado por Moyano (1948) y Martinič (1995). }\end{array}$ \\
\hline Verbena sp. (sin datos, P. 131) (CTES) & ánkuis, tomillo & $\begin{array}{l}\text { La Inf. de su PA era Ing. como depurativo sanguíneo, contra } \\
\text { hipertensión y cefalalgias. }\end{array}$ \\
\hline \multicolumn{3}{|l|}{ WINTERACEAE } \\
\hline Drimys winteri J.R. Forst. \& G. Forst. & Canelo & $\begin{array}{l}\text { Lista (1894) cita la dec. de su CO Ing. como antiescorbútico y contra la } \\
\text { fiebre reumática. Según Martinič (1995) con sus TA se confeccionaban } \\
\text { los parantes de los toldos que empleaban como viviendas. }\end{array}$ \\
\hline \multicolumn{3}{|l|}{ SIN IDENTIFICAR } \\
\hline- & $\begin{array}{l}\text { Pícharo, } \\
\text { Pécharo }\end{array}$ & $\begin{array}{l}\text { Sus RA eran comidos antiguamente. Lista (2006) también cita este } \\
\text { mismo uso en forma cruda o asada. }\end{array}$ \\
\hline- & Luche & Se hacen panes y se hornea para desecar y conservar. \\
\hline- & Chérke & Sus FR eran comidos antiguamente. \\
\hline
\end{tabular}




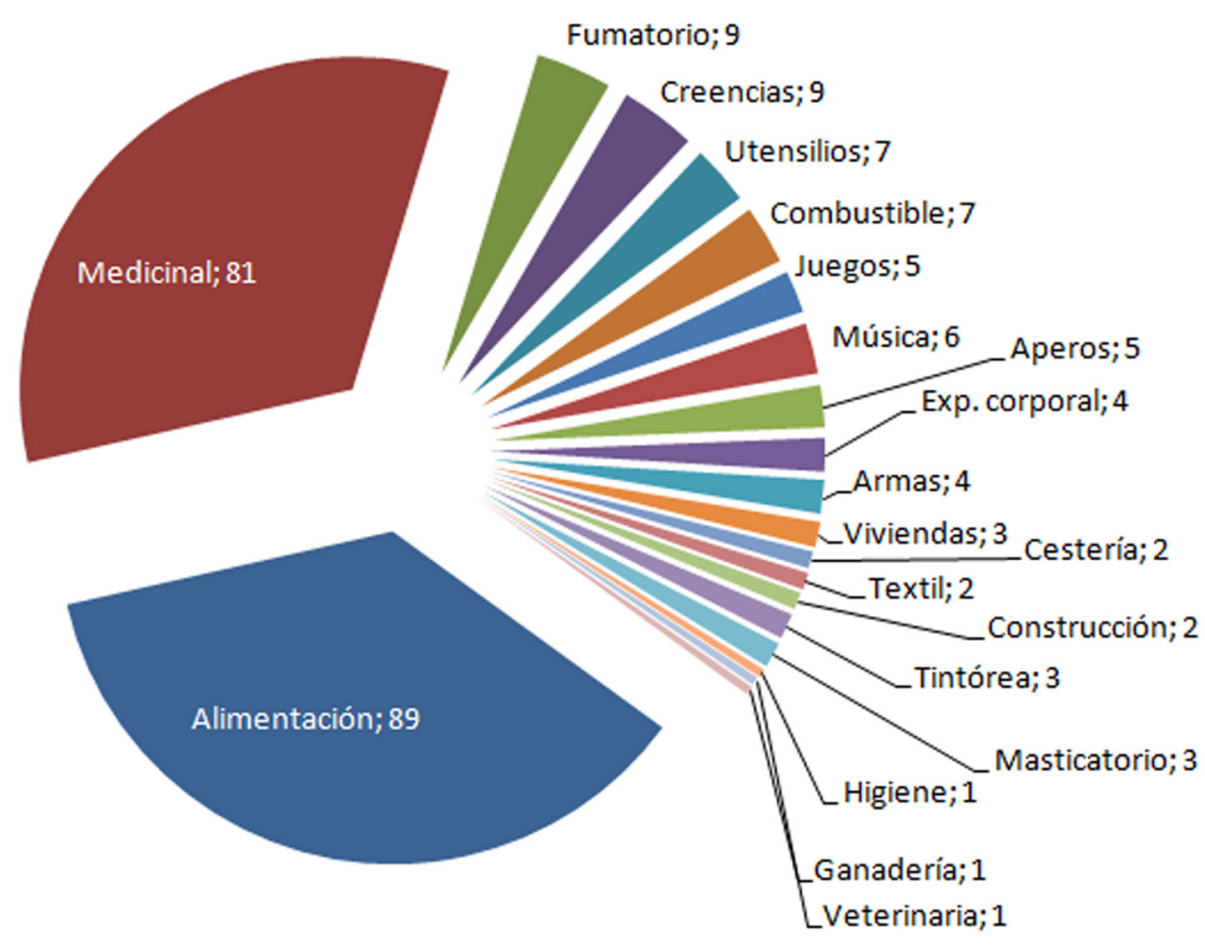

Fig. 2. Participación relativa de las categorías de usos registradas. Figura en color en la versión en línea http:// www.ojs.darwin.edu.ar/index.php/darwiniana/article/view/867/1183

Comparación con la etnobotánica de los Selk'nam de Tierra del Fuego

Como resultado de la comparación entre los datos etnobotánicos Aonik'enk descritos en la Tabla 1 y aquellos de los Selk'nam de Tierra del Fuego publicados por Martínez Crovetto (1968) se observa, en primer lugar, la coincidencia en que la mayoría de ellos se refieran al uso alimenticio de las plantas. Sin embargo, estos usos representan una proporción mucho mayor para los Selk'nam $-90 \%$ del total- que para los Aonik'enk -36,5 \%-, así como los usos medicinales de estos últimos -33 $\%$ - superan holgadamente a los registrados entre los Selk'nam -menores al $10 \%$-.

De la comparación exhaustiva entre las aplicaciones específicas de las plantas registradas para ambos pueblos se desprende que solo $31 \mathrm{de}$ los datos etnobotánicos resultan idénticos. Esto significa que se cita el mismo uso sobre la misma especie vegetal solo en el $12,7 \%$ de los datos totales Aonik'enk, siendo más de las $3 / 4$ partes de dichas similitudes (24) correspondientes a usos de índole alimenticio. Sin embargo, la semejanza entre ambas etnobotánicas resulta mayor si se pondera este resultado con el número de especies vegetales comunes sobre las que se inquirió en uno y otro caso (solo 49 especies), resultando un índice de usos idénticos por especie compartida (cociente entre ambas variables) relativamente elevado $(0,63)$.

\section{DISCUSIÓN Y CONCLUSIONES}

De acuerdo con los resultados obtenidos, la menor cantidad de usos medicinales hallados respecto a los alimenticios se corresponde con la situación típica hallada en la etnobotánica indígena de tierras bajas de la Argentina (Arenas, 1987; Scarpa, 2009) por la cual, en su medicina de corte chamánico, las plantas no habrían tenido un papel terapéutico descollante. Esta afirmación resulta coincidente con lo expresado por Spegazzini (1884: 237) para los 
"médicos tehuelches" en cuanto a que: "Pocas son las plantas que emplean, más bien usa fricciones, vejigatorios, sudores, movimiento y dieta; conoce también algunas plantas purgantes...". Sin embargo, la gran cantidad de usos medicinales registrado (81) podría estar indicando casi cien años más tarde ciertas adquisiciones en este ámbito cultural procedente de otros grupos humanos. En efecto, más allá del intercambio de algunas especies de plantas con indígenas del Neuquén referidas en la bibliografía (Martinič, 1995), desconocemos cuáles habrían sido prácticas culturales asociadas a los vegetales que seguramente habrían adquirido los Aonik'enk en función de las profundas transformaciones socioculturales acaecidas para este grupo humano a la llegada de aquellos autores cuyas fuentes citamos en este trabajo. Pruebas de esto último son las citas de Lista (2006) y de Spegazzini (1884: 226) donde se afirma a finales del siglo XIX que "la vida de los Aónik(Q]n actuales debe ser absolutamente diferente de la de sus antepasados" y que "sus costumbres antiguas han desaparecido".

Resulta muy sugerente que más del $18 \%$ de los datos (19) recabados en la bibliografía hayan sido referidos a una sola etnoespecie ("chorch"), correspondientes a varias especies del género Berberis. Esto no solo se debería a la importancia de estas especies botánicas para los Aonik'enk (corroboradas por los datos de MC), sino también por la falta de experticia botánica de quienes registraron tales datos. Esto último, sin duda, habría sesgado desproporcionadamente las consultas hacia aquellos elementos conspicuos de la vegetación, como los "calafates" fácilmente reconocibles por los neófitos, en detrimento de la rica diversidad vegetal existente en la zona, menos notables para éstos. Prueba de ello es lo señalado por Spegazzini (1884: 227) quien afirma que “...frutas no hay sino las del calafate (Berberis heterophylla) y la de una especie de frutilla en la precordillera; comen también las raíces del macachi (Arjonia tuberosa), y de una especie de llarreta (Bolax glebaria)". Asimismo, también resulta destacable que prácticamente la totalidad de datos acerca de los árboles del género Nothofagus Blume y de las cañas del género Chusquea Kunth halla provenido de la bibliografía y que MC no haya registrado nombres vernáculos para ninguna de estas especies. La razón de esto último, en vistas a la importancia cultural de estas especies según se desprende de los usos consignados por Hesketh-Prichard (1902), Lehmann-Nitsche (1908) y Martinič (1995), podría indicar que los materiales provenientes de las mismas habrían sido obtenidos por intercambio con otros pueblos. Reafirma dicha hipótesis el hecho de que esta misma situación fuera explícitamente consignada para otras especies (como Peumus boldo, Fabiana imbricata y Maytenus boaria) y que el bosque subantártico -donde dichos árboles y cañas vegetan- no constituían ámbitos que frecuentaran asiduamente los Aonik'enk (en efecto, ninguna de las comunidades donde MC realizó sus entrevistas se hallaba localizada en dicha región, tal como se observa en el mapa de la Fig. 1).

Registramos al menos tres datos etnobotánicos que resultarían totalmente novedosos para la zona, según la consulta realizada en bases de datos (Johnson, 2018 [1999]; USDA, 2019) y en bibliografía etnobotánica de la región (Ladio \& Lozada, 2000; Domínguez Díaz, 2010; Ciampagna, 2014; entre otras). Uno es el consumo de las raíces asadas de una especie del género Rumex L. citado por Fitz Roy (1839), Lista (1894) y por Schmid (1964) [1858/65], dato congruente con lo citado para otras regiones del mundo donde algunas especies de este género que presentan raíces engrosadas son consumidas como alimento, tales como las de $R$. crispus y R. obtusifolius (Wild cookery, 2019). Los otros dos son el empleo masticatorio de las hojas de Chuquiraga avellanedae -"de una amargura insoportable” según Spegazzini (1884)- y el uso de las raíces de Mulguraea tridens como dientes de peines unidos por ataduras citado por MC y por Martinič (1995). Merecen una mención especial algunas especies de hongos y plantas asociadas a seres no humanos denominados "espíritus" en las fuentes. Uno de ellos es el "de la piedra" (ájchen o ájchün) al cual está relacionado Agaricus sp. por ser su alimento (de donde deriva su nombre vulgar) y Calvatia spp. de cuyas glebas dichos "espíritus" extraían el tinte empleado por ellos en las pinturas rupestres de la región. La otra entidad espiritual mencionada es "maipe" o "espíritu malo" cuyos efectos nefastos se ahuyentaban mediante rituales precautorios consistentes en quemar las matas de Ribes magallanicum o de algunas especies de Senecio L. (S. patagonicus, S. neaei o S. trifurcatus). 
Consideramos que los resultados obtenidos de la comparación entre la etnobotánica Aonik'enk y la de los Selk'nam (u Onas) de Tierra del Fuego resultarían significativos, debido a que los datos provenientes de cada una de ellas fueron registrados por el mismo investigador, con los mismos criterios y prácticamente al mismo tiempo (con dos años de diferencia). Las escasas coincidencias halladas $(12,6 \%)$ sin embargo, se deberían tanto a diferencias de índole cultural como ecológicas de las distintas regiones que cada grupo ocupaba. En efecto, solo el $41 \%$ de las plantas sobre las que se inquirió en uno y otro caso fueron idénticas, ya que la representatividad en Tierra del Fuego (donde habitaban los Selk'nam) de los elementos del bosque subantártico es mucho mayor en términos relativos que los de la estepa de la provincia de Santa Cruz (Aonik'enk). Sin embargo, si consideramos solo los usos coincidentes entre las especies botánicas compartidas, la proporción de datos idénticos asciende a más del $60 \%$, con lo cual se confirma la existencia de indudables vinculaciones culturales plasmadas en la etnobotánica de ambos grupos.

Los resultados de este trabajo, junto con los publicados sobre su fitonimia por Scarpa et al. (2020), constituyen la mayor contribución a la etnobotánica Aonik'enk al presente gracias a los datos inéditos de $\mathrm{MC}$ puestos aquí en valor y a la cantidad y diversidad de datos compilados. En efecto, más de la mitad de los mismos (57 $\%, 139$ datos) corresponden exclusivamente a las informaciones documentadas por $\mathrm{MC}$ en el año 1967. Esto, sumado a la imposibilidad de registrarlos en la actualidad, demuestra el valor extraordinario que los datos de Raúl Martínez Crovetto, que aquí se ponen en valor y se analizan, poseen para la etnobotánica argentina.

Se citan por vez primera para nuestro país los usos comestibles de la raíz de una especie del género Rumex y de la parte aérea de Chuquiraga avellanedae, así como los usos de Mulguraea tridens para la confección de peines. En total se pudieron identificar 244 datos etnobotánicos netos sobre este pueblo referidos a 117 taxa botánicos, la mayoría los cuales corresponden a usos alimenticios (90; $36,7 \%)$ y medicinales $(81 ; 33 \%)$.

\section{AGRADECIMIENTOS}

A las autoridades del Instituto de Botánica del Nordeste (IBONE) por las facilidades brindadas durante el registro de las fuentes primarias y la consulta de ejemplares de herbario aquí citados, especialmente a Carolina Peichoto y a los técnicos Sandra y Walter Miranda y Deborah Olmedo, así como a los encargados de su biblioteca. Al Consejo Nacional de Investigaciones Científicas y Técnicas y al Museo Argentino de Ciencias Naturales por facilitarnos sus instalaciones.

\section{BIBLIOGRAFIA}

Arenas, P. 1987. Medicine and magic among the maká indians of the Paraguayan Chaco. Journal of Ethnopharmacology 21: 279-295. DOI: https://doi.org/10.1016/0378-8741(87)90104-8

Belardi, J.; F. Carballo Marina, A. Nuevo Delaunay \& H. Angelis. 2013. Raspadores de vidrio y de gres cerámico en la Reserva Tehuelche (Aonikenk) de Camusu Aike: aportes al conocimiento de poblaciones indígenas de los siglos XIX y XX en el territorio de Santa Cruz. Relaciones de la Sociedad Argentina Antropología 38: 37-57.

Casamiquela, R. M. 1965. Rectificación y ratificaciones. Hacia una interpretación definitiva del panorama etnológico de la Patagonia y área septentrional adyacente. Bahía Blanca: Universidad Nacional del Sur.

Censabella, M. 1999. Las lenguas indigenas de la Argentina. Buenos Aires: Eudeba.

Ciampagna, M. L. 2014. Estudio de la interacción entre grupos cazadores recolectores de la Patagonia y las plantas silvestres: el caso de la costa norte de Santa Cruz durante el Holoceno medio y tardio. Tesis doctoral, Universidad Nacional de La Plata.

Ciampagna, M. \& A. Capparelli. 2012. Historia del uso de las plantas por parte de las poblaciones que habitaron la Patagonia Continental Argentina. Revista de Arqueología 6: 45-75.

Childs, H. 1997 [1936]. El Jimmy, Bandido de la Patagonia. Punta Arenas: Universidad de Magallanes.

Correa, M. N. 1984. Flora Patagónica. Buenos Aires: Instituto Nacional de Tecnología Agropecuaria.

Domínguez Díaz, E. 2010. Flora de interés etnobotánico usada por los pueblos originarios: Aónikenk, Selk'nam, Kawésqar, Yagan y Haush en la Patagonia Austral. Dominguezia 26: 19-29.

Embon, A. 1950. Fuentes Históricas con noticias etnográficas $y$ arqueológicas del indígena patagón (Aoni kenk). Tesis doctoral, Universidad Nacional de La Plata. 


\section{G. F. SCARPA ET AL. Etnobotánica Aonik'enk (Tehuelches de Santa Cruz) inédita}

Escalada, F. 1949. El complejo "tehuelche". Estudios de etnografia patagónica. Buenos Aires: Coni.

Fernández Garay, A. 1998. El tehuelche, una lengua en vías de extinción. Estudios Filológicos. Valdivia: Universidad Austral de Chile. DOI: https://doi.org/10.1086/466489

Fernández Garay, A. 2004. Diccionario Tehuelche-Español / Español-Tehuelche. Escuela de Investigación de Estudios Asiáticos, Africanos y Amerindios (CNWS). Leiden: Universidad de Leiden. DOI: https://doi.org/10.1075/ s1.31.3.07hau

Fitz Roy, R. 1839. Narrative of the surveying voyages of His Majesty's Ships Adventure and Beagle between the years 1826 and 1836, describing their examination of the southern shores of South America, and the Beagle's circumnavigation of the globe. Proceedings of the second expedition, 1831-36, under the command of Captain Robert Fitz-Roy, R.N. Londres: H. Colburn. [Consulta on-line http://darwin-online.org.uk/content/ frameset?itemID $=\mathrm{F} 10.2 \&$ viewtype $=$ text\&pageseq $=1]$.

GBIF. 2019. Global Biodiversity Information Facility. Disponible en: https://www.gbif.org/ [Acceso: Mayo-Julio de 2019].

Harrington, T. 1946. Contribución al estudio del indio Gününa Küne. Revista del Museo de La Plata (nueva serie) II, Antropología 14: 237-275.

Hesketh-Prichard, H. 1902. Through the Heart of Patagonia. Nueva York: D. Appleton \& Cía.

Johnson, T. 2018 [1999]. CRC Ethnobotany Desk Reference. Boca Raton: CRC Press. DOI: https://doi. org/10.1201/9781351070942

Ladio,A.H. \& M. Lozada. 2000. Edible Wild Plant Use in a Mapuche Community of Northwestern Patagonia. Human Ecology 28: 53-71. DOI: https://doi.org/10.1023/A:1007027705077

Lazzari, A. \& L. Quarleri (coords.). 2015. Pueblos indígenas y antropología en Argentina. Balances y perspectivas (19842014). Papeles de Trabajo IDAES 9(16): 14-352.

Lehmann-Nitsche, R. 1908. Patagonische Gesänge und Musikbogen. Anthropos 3: 916-940.

Lista, R. 1975. Mis exploraciones y descubrimientos en la Patagonia 1877-1880. Buenos Aires: Maryma.

Lista. R. 2006. Viaje a la Patagonia Austral (1879): Los indios tehuelches. Una raza que desaparece (1894). Buenos Aires: Continente.

Martínez Crovetto, R. N. 1968. Estudios etnobotánicos IV. Nombres de plantas y su utilidad, según los indios Onas de Tierra del Fuego. Etnobiológica 3: 1-20.

Martinič, M. B. 1995. Los Aónikenk. Historia y Cultura. Punta Arenas: Universidad de Magallanes. http://www. memoriachilena.gob.cl/602/w3-article-8404.html
Musters, J. Ch. 1964. Vida entre los Patagones. Un año de excursiones por tierras no frecuentadas desde el Estrecho de Magallanes hasta el río Negro. Buenos Aires: Solar/ Hachette.

MycoBank Database. 2019. Fungal Databases, Nomenclature \& Species Banks. International Mycological Association. Disponible en: http://www.mycobank.org/ [Acceso: Mayo-Julio de 2019].

Nacuzzi, L. R. 2005. Identidades impuestas. Tehuelches, aucas y pampas en el norte de la Patagonia. Buenos Aires: Sociedad Argentina de Antropología.

Onelli, C. 1904. Trepando los Andes. Buenos Aires: Compañía de Billetes de Banco.

Outes, F. F. 1905. La edad de piedra en la Patagonia. Anales del Museo Nacional de Buenos Aires 5: 203-359.

Palermo, M. A. 1986. Reflexiones sobre el llamado "complejo ecuestre" en la Argentina. Runa 16: 157-178.

Rodríguez, M. E. \& W. Del Río. 2000. Los tehuelches. Un paseo etnohistórico, en Gobernación de Santa Cruz (ed.), El Gran Libro de La Provincia de Santa Cruz, pp. 428460. Barcelona: Alfa-Milenio.

Rodríguez, M. E.; L. Horlent \& colaboradores tehuelches y selk'nam. 2016. Tehuelches y selk'nam: no desaparecimos. Buenos Aires: Ministerio de Educación y Deportes.

Roncaglia, G. 1884. Da Punta Arenas a Santa Cruz. Bolettino della Societá Geografica Italiana Serie II, Vol. IX, Año XVIII, Fasc. 10, Roma.

Rosso, C. N. 2012. La etnobotánica de los grupos mocovies de la reducción de San Javier, en el Gran Chaco, durante el siglo XVIII. Tesis Doctoral, Facultad de Filosofía y Letras, Universidad de Buenos Aires.

Rosso, C. N. \& G. F. Scarpa. 2012. Identificaciones botánicas de las plantas empleadas entre los mocovíes en la reducción San Javier durante el siglo XVIII a partir de la obra de Florián Paucke, S.J., en P. Arenas (ed.), Etnobotánica en zonas áridas y semiáridas del Cono Sur de Sudamérica, pp. 45-70. Buenos Aires: Sigma.

Saletta, M. J. 2015. Excavando Fuentes La tecnología, subsistencia, movilidad y los sistemas simbólicos de Shelk'nam. Yámana/ Yaghan y Aonikenk entre los siglos XVI y XX analizadas a partir de los registros escritos $y$ arqueológicos. Tesis Doctoral, Universidad de Buenos Aires.

Scarpa, G. F. 2009. Etnobotánica médica de los indígenas chorote y su comparación con la de los criollos del Chaco semiárido (Argentina). Darwiniana 47: 92-107. DOI: https://doi.org/10.14522/darwiniana.2014.471.43 
Scarpa, G.F.; L. M. Anconatani, C. N. Rosso \& N. C. D. Huircapán. 2020. La etnobotánica Aonik’enk (Tehuelches de Santa Cruz, Argentina) inédita de Raúl Martínez Crovetto: Fitonimia, correspondencias botánicas y análisis nomenclatural. Boletín de la Sociedad Argentina de Botánica 55(1): 137-157.

Schmid, T. 1964 [1858/65]. Misionando por Patagonia Austral 1858-1865. Usos y costumbres de los Indios Patagones. Buenos Aires: Academia Nacional de la Historia.

Secretaría de Cultura de la Nación. 2018. Los pueblos originarios en Argentina, hoy. [online]. Disponible en: https://www.cultura.gob.ar/dia-internacional-de-los-pueblosindigenas_6292

Siffredi, S. \& M. Matarrese. 2004. Espiritualidad tehuelche meridional (aónikenk). Recomponiendo las astillas de la memoria, en M.S. Cipolletti (coord.), Los mundos de abajo. Los mundos de arriba. Individuo y sociedad en las tierras bajas, en los Andes y más allá, pp. 203-218. Quito: Abya Yala.

Spegazzini, C. 1884. Costumbres de los patagones. Conferencia dada en los salones de la Sociedad Científica Argentina el 2 de mayo de 1884. Anales de la Sociedad Cientifica Argentina 17: 221-240.
Species Fungorum.2019. RBG Kew databases, http://www. speciesfungorum.org/ [Consulta Mayo-Julio de 2019].

The Plant List. 2013. Version 1.1. Published on the Internet: http://www.theplantlist.org/ [Consulta Mayo de 2019].

Tropicos Missouri Botanical Garden. 2019. http://www. tropicos.org

USDA. 2019. The Plants Database. Natural Resources Conservation Service (NRCS), United States Department of Agriculture, http://plants.usda.gov [Consulta 23 December 2019).

Viegas Barros, J. P. 2011. Las lenguas argentinas indigenas en peligro. Conferencia pronunciada en el marco del IV Encuentro de Lenguas en Riesgo, Instituto Nacional de Antropología e Historia, México DF, 23-26 de septiembre de 2011.

Vignati, M. A. 1936. Las culturas indígenas de Patagonia, en: R. Levene (ed.), Historia de la Nación Argentina Vol. I, pp. 591-645. Buenos Aires: Junta de Historia y Numismática Americana.

Wild cookery. 2019. Blog on-line. https://wildcookery. wordpress.com/ [Consulta: Diciembre de 2019].

Zuloaga, F. O.; M. J. Belgrano \& C. A. Zanotti. 2019. Actualización del catálogo de plantas vasculares del Cono Sur. Darwiniana, nueva serie 7(2): 208-278. DOI: https:// doi.org/10.14522/darwiniana.2019.72.861 